\title{
Farklı Şiddetteki Diz Osteoartritli Hastalarda Kinezyofobi, Ağrı, Fonksiyonel Durum ve Öz- Etkililik Arasındaki İlişkinin İncelenmesi
}

Investigation of the Relationship Between Kinesiophobia, Pain, Functional Status and Self Efficacy in Patients with Knee Osteoarthritis of Different Severity

\author{
Nurhayat KORKMAZ1 (D), Gürsoy COŞKUN²(D), İsmail BOYRAZ3 (D) \\ 1 1Arş. Gör., Karadeniz Teknik Üniversitesi, Sağlık Bilimleri Fakültesi, Fizyoterapi ve Rehabilitasyon, Trabzon, Türkiye \\ ${ }^{2}$ Doç. Dr., Hacettepe Üniversitesi, Fizik Tedavi ve Rehabilitasyon Fakültesi, Ankara, Türkiye \\ ${ }^{3}$ Doç. Dr., Devapark Tıp Merkezi, Fiziksel Tıp ve Rehabilitasyon, Ankara, Türkiye
}

\section{ÖZ}

Amaç: Bu çalışmamızın amacı farklı şiddetteki diz osteoartritli hastalarda kinezyofobi, ağrı, fonksiyonel durum ve öz-etkililik arasındaki ilişkiyi incelemektir Gereç ve Yöntem: Çalışmaya Kellgren Lawrence sınıflamasına göre evre 2 ve evre 3 diz osteoartritli 72 birey dahil edildi. Kinezyofobi için Tampa Kinezyofobi Ölçeği (TKÖ), ağrı için Vizüel Analog Skalası (VAS) kullanıldı. Bireylerin fonksiyonel durumu The Western Ontario and McMaster Universities Arthritis Indeks (WOMAC) ile değerlendirildi. Öz-etkililik Artritlerde Öz Etkililik Ölçeği (AÖÖ) kullanılarak değerlendirildi. Sonuçlar: Evre 2 ve evre 3 hastalarının WOMAC ile TKÖ sonuçları arasında pozitif yönde orta düzeyde ilişkili bulundu $(p=0,048 ; r=0,332$, $p=0,024 ; r=0,376)$. Her iki evrede AÖÖ ile TKÖ sonuçları $(p=0,002 ; r=0,449, p=0,016 ; r=0,390)$ ve AÖÖ ile WOMAC sonuçları negatif yönde orta düzeyde ilişkiliydi ( $p=0,000 ; r=0,580, p=0,010 ; r=0,426)$. Evre 3 hastalarının evre 2'ye göre düşük öz-etkililik $(p=0,011)$, yüksek kinezyofobiye sahip oldukları görüldü $(p=0,009)$. Evre 2 hastalarının VAS ile WOMAC sonuçları arasında anlamlı ilişki saptanmazken $(p=0,281$; $r=0,184)$ evre 3 hastaları arasında pozitif yönde orta düzeyde ilişki görüldü ( $p=0,017 ; r=0,397)$. Tartışma: Diz osteoartritli hastalarda kinezyofobi ve kişinin aktiviteye yapabileceğine dair kendine olan inancının fonksiyonel durumu etkileyen belirteçlerden biri olduğu ve bu parametrelerin radyolojik şiddetle ilişkili olduğu saptandı. Dolayısıyla bu bireylerin değerlendirme ve tedavi programlarında bu parametrelere de dikkat edilmesi gerektiği düşünülmektedir.

Anahtar Kelimeler: Diz; Osteoartrit; Ağrı; Fonksiyonel Durum; Öz etkililik.

\section{ABSTRACT}

Purpose: The aim of this study is to examine the relationship between kinesophobia, pain, functional status and self-efficacy in patients with knee osteoarthritis of different severity. Material and Methods: The study included 72 individuals with stage 2 and 3 knee osteoarthritis according to the Kellgren Lawrence classification. Tampa Kinesiophobia Scale (TSK) for kinesiophobia; Visual Analogue Scale (VAS) for pain, Western Ontario and McMaster Universities Arthritis Index (WOMAC) for functional status, Self-Efficacy Scale for Arthritis (ASES) for self-efficacy were used, respectively. Results: Positive correlations were found between WOMAC and TSK of stage 2 and $3(p=0.048 ; r=0.332, p=0.024$; $r=0.376)$. In both phases, ASES and TSK $(p=0.002 ; r=0.449, p=0.016 ; r=0.390)$ and ASES and WOMAC were moderately negatively correlated $(p=0.000 ; r=0.580, p=0.010 ; r=0.426)$. It was observed that stage 3 had lower self-efficacy $(p=0.011)$ and higher kinesiophobia compared to stage $2(p=0.009)$ patients. While there was no correlation between VAS and WOMAC of stage $2(p=0.281 ; r=0.184)$, moderate positive correlation was found in stage $3(p=0.017 ; r=0.397)$. Discussion: In patients with knee osteoarthritis, it was determined that kinesiophobia and self-belief that one can do the activity were the markers affecting the functional status and these parameters were related to radiological severity. Therefore, it is thought that attention should be paid to these parameters in the evaluation and treatment programs of these individuals.

Keywords: Knee; Osteoarthritis; Pain; Functional Status; Self Efficacy. 
Dünya çapında yetişkinlerde en sık görülen eklem hastalığı osteoartrittir (OA). Birinci basamak sağlık merkezlerine gelen yetişkinlerde, özellikle 45-65 yaşları arasında en sık karşılaşılan sağlık sorunlarından biridir (Sanchez-Heran, AgudoCarmona, Ferrer-Pena ve ark., 2016). Osteoartritli hastalarda temel şikayet ağrıdır (Serban, Porojan, Deac ve ark., 2016). Periferik veya merkezi nosiseptif nöronların artan hassasiyeti, diz osteoartritinde ağrı deneyimine katkıda bulunur (Neogi, Guermazi, Roemer ve ark., 2016). Sağlık davranışlarını inceleyen sosyal bilişsel modellerde bireylerin hastalıklarına ilişkin inançlarına veya zihinsel temsillerine odaklanılmıs ve insanların hastalıkla ilgili bilişsel temsillerinin, duygusal tepkilerini belirlediği, başa çıkma stratejilerine rehberlik ettiği ifade edilmiştir (Pouli, Das Nair, Lincoln ve ark., 2014). Vücut yapıları bir yaralanmaya uğradığında ortaya çıkan ağrı, kişinin yaralanma sonrası hareketlerinde kısıtlamalara neden olur ve iyileşme olsa bile kişide hareket korkusuna neden olabilir. Diz OA'ı bireylerde aktivitelerden kaynaklanan ağrı korkusunun kronik ağrı, sakatlık, endişe, depresyon ve tedavinin etkinliği ile ilgili parametreler üzerinde anlamlı etkisi olan bilişsel bir faktör olduğu bildirilmiştir (Areeudomwong ve Buttagat, 2017).

Semptomatik diz $O A^{\prime}$ nın önemli klinik belirtilerinden biri bireylerin yaşadığı fonksiyonel kısıtılıklardır. Diz osteoartriti kronik ve ilerleyen bir hastalık olduğu için kliniğe gelen hastaların fiziksel fonksiyonlarının zamanla bozulduğu görülmektedir (Oiestad, White, Booton ve ark., 2016). Bu durum da bireylerin günlük yaşam aktivitelerindeki faaliyetlerden ödün vermeleriyle sonuçlanır. Aynı zamanda iş, eğlence, sosyal ilişkileri ve yaşam kaliteleri de etkilenir (Araujo, Castro, Daltro ve ark., 2016). Hareket etme korkusunun osteoartritli hastalarda klinik sonuçları etkilediği bildirilmiştir. Bu nedenle, OA' nın neden olduğu fonksiyonel kısıtlamaları azaltmayı amaçlayan mevcut müdahalelerin ana hedeflerinden biri de hareket korkusunu çözümlemektir (Shelby, Somers, Keefe ve ark., 2012). Öz-etkililik, bireyin sonuç üretmek için gereken davranışı başarıyla uygulayabileceğine inancı olarak tanımlanmıştır (Harrison, 2004; Brady, 2011). Osteoartritli bireylerde ağrı, hareket kısıtlılığı, kas güçsüzlüğü, fonksiyon azalması gibi faktörler fiziksel yetersizliği artıırır, bireylerin hareketlerini kısıtlayarak ve beden imajı bozukluklarına neden olarak öz-etkililik algısını etkiler (Doğan, Göriş ve Demir, 2016).

Literatürde diz $O A^{\prime}$ । bireylerde ağrı, fiziksel aktivite, fonksiyonel durum ve dengeyi değerlendiren çok sayıda çalışma mevcuttur. Fakat bu çalışmaların çoğunda sağlıklı kontrollerle karşılaştırmalar yapılmıştır. Yapılan sistematik derlemelerde değerlendirmelerin radyolojik şiddete göre de yapılması gerektiği belirtilmektedir (Lawson, Morrison, Blaxland ve ark., 2015; Hatfield, Morrison, Wenman ve ark.,2016). Kinezyofobi ve öz-etkililiğin değerlendirildiği çalışmalar nadir olmakla birlikte yapılan sistematik derlemelerde kinezyofobi ve özetkililik ile ilgili daha fazla çalışmaya intiyaç olduğu belirtilmiştir (López-Bravo, Zamarrón-Cassinello, Touche ve ark., 2020; Benyon, Hill, Zadurian ve Mallen, 2010). Ayrıca bu parametrelerin radyolojik şiddete göre değişimleri ve ilişkileri incelenmemiştir. Bu nedenle çalışmamızda farklı radyolojik şiddete göre $O A^{\prime}$ । ı bireylerin ağrı, kinezyofobi, fonksiyonel durum ve öz-etkililiklerinin değerlendirilmesi literatüre ve klinisyenlere önemli katkı sağlayacaktır. Bu nedenle bu çalışmanın amacı farklı şiddetteki diz OA' ı hastalarda ağrı, kinezyofobi, fonksiyonel durum ve öz-etkililik sonuçları arasındaki ilişkinin incelenmektir. Çalışmamızın hipotezleri: (1) diz OA' ı hastalarda ağrı, kinezyofobi, fonksiyonel durum ve öz-etkililik arasındaki ilişki vardır, (2) diz OA' ı hastalarda radyolojik şiddete göre ağrı, kinezyofobi, fonksiyonel durum ve öz-etkililik sonuçları arasında farklılıklar vardır.

\section{GEREÇ VE YÖNTEM}

Çalışmamız Hacettepe Üniversitesi Fizyoterapi ve Rehabilitasyon Fakültesi'nde yapıldı. Hacettepe Üniversitesi Girişimsel Olmayan Klinik Araştırmalar Etik Kurulu'ndan GO 18/129-12 karar numarası ile çalışma onayı alındı. Katıımcılar çalışmanın içeriği hakkında bilgilendirildi ve bilgilendirme sonunda çalışmaya gönüllü olarak katıldıklarına ilişkin aydınlatılmış onam formunu okuyup, imzaladı.

Çalışmamıza Kellgren Lawrence sınıflandırmasına göre evre 2 ve evre 3 diz OA tanısı almış 40-85 yaş aralığında toplam 72 gönüllü kişi dahil edildi. Alt ekstremite cerrahisi öyküsü, travma, tendinit, bursit, bağ ve menisküs sorunları, değerlendirmeleri etkileyebilecek nörolojik veya kardiyopulmoner hastalık ve alt ekstremitede dizde yansıyan ağrıya neden olabilecek problem geçirmiş kişiler, gut, romatoid artrit gibi iltihaplı romatizmal hastalığı olan, son 6 aydır fizik tedavi ve rehabilitasyon programına katılmış ve diz enjeksiyonu yapılmış bireyler çalışmaya dahil edilmedi. Veri Toplama Araçları

Kinezyofobi Değerlendirmesi: Tampa Kinezyofobi Ölçeği (TKÖ) kullanıldı. Bu ölçek 1991'de Miller ve 
diğerleri tarafından geliştirilmiştir. Hareketle yeniden yaralanma korkusunu belirlemek için geliştirilmiş 17 soruluk bir ölçektir. Testin sonucu 17 ile 68 puan arasında olabilir. Yüksek puan yüksek kinezyofobi, düşük puan düşük kinezyofobi anlamına gelir (Yılmaz, Yakut, Uygur ve ark., 2011; Erden, Altuğ, Malkoç ve ark., 2016).

Ağrı Değerlendirmesi: Ağrının şiddetini ölçmek için Vizüel Analog Skala (VAS) kullanıldı. VAS 10 cm'lik bir çizgiden oluşur. Satırın başlangıcı "0", "acı yok" ve bitiş çizgisi "10", "acı dayanılmaz" olarak belirtilir (Yılmaz, Yakut, Uygur ve ark., 2011).

Fonksiyonel Durum Değerlendirmesi: The Western Ontario ve McMaster Universities Artritis Index (WOMAC) kullanılarak değerlendirildi. Bu test, kalça / diz osteoartriti olan bireylerin değerlendirilmesinde geçerliliği ve güvenilirliği kanıtlanmış yaygın olarak kullanılan bir ölçektir. Osteoartritin neden olduğu sakatlığı değerlendirir. Ağrı, sertlik ve fiziksel fonksiyon olarak 3 kısımdan oluşur. Toplam 24 maddeden oluşmaktadır. Likert ölçeği ile puanlanır. Ağrı ve gerginlik seviyesi için 0 ile 4 arasında bir puan verilir. Testin sonucu 0 ile 96 puan arasında olabilir. Yüksek puan, kötü işlevsel durumu gösterir (Tüzün, Eker, Aytar ve ark., 2005; Cruz-Almeida, King, Goodin ve ark., 2013).

Öz-Etkililik Değerlendirmesi: Artritlerde Öz-etkililik Ölçeği (AÖÖ), 1989 yılında, artrit tanısı alan bireylerin öz- etkililiklerini ölçmek için Kate Lorig ve arkadaşları tarafından geliştirilmiştir. Ağrılı durumlarda, işlevlerde ve diğer durumlarda özetkililik için 3 alt değerlendirmeye sahip 10 puanlık görsel ölçek toplamda 20 ifade içermektedir. İlk 5 ifade, ağrıda öz-etkililik ile ilgili bir alt değerlendirmede yer almaktadır. İşlevlerdeki öz-etkililik, artritten etkilenen el ve ayak eklemlerinin işlevlerinin etki düzeyini ölçer. Aşağıdaki 9 ifade bu alt değerlendirmede yer almaktadır. Diğer durumlarda, özetkililik değerlendirmesi, artritli bir bireyin semptomlarla başa çıkma yeteneğini ölçer. Bu alt değerlendirmede 6 ifade yer almaktadır. Toplam 20 ifade "Hiç emin değilim, 1 puan" ve "10 puan çok eminim" şeklinde ifade ediliyor. Ölçekte 20 ile 200 puan arası alınabilir. Yüksek puan, yüksek öz-etkililik anlamına gelir (Ünsal ve Kaşıkçı, 2008; Brand, Nyland, Henzman ve ark., 2013).

\section{Istatistiksel Analiz}

Veri analizi için SPSS 24.0 (IBM SPSS Statistics 24 yazılımı (Armonk, NY: IBM Corp.) paket programı kullanıldı. Sürekli değişkenler ortalama \pm standart sapma, kategorik değişkenler sayı ve yüzde olarak ifade edildi. Parametrik test varsayımları sağlandığı zaman bağımsız grup farklılıklarının karşılaştırılmasında iki ortalama arasındaki farkın önemliliği kullanıldı. Varsayımları sağlanmadığı zaman ise bağımsız grup farklılıklarının karşılaştırılması Mann Whitney $U$ testi ile yapıldı. Kategorik değişkenler arasındaki farklılıkların incelenmesinde Ki-kare kullanıldı. Değişkenler arasındaki ilişki Spearman korelasyon analizi ile yapıldı. Tüm analizlerde $p<0,05$ istatistiksel olarak anlamlı kabul edildi.

\section{SONUÇLAR}

Kellgren Lawrence radyolojik evrelemesine göre araştırmaya katılan 40-85 yaş arası bireyler evre 2 ve evre 3 olarak iki gruba ayrılmıştır. Her gruba 36 kişi dahil edilmiştir. Bireylerin fiziksel özellikleri Tablo 1'de gösterilmektedir.

Tablo 1. Bireylerin fiziksel özellikleri.

\begin{tabular}{|c|c|c|c|c|}
\hline & & Evre 2 & Evre 3 & $\mathbf{p}$ \\
\hline \multirow[t]{2}{*}{ Yaş } & $A O \pm S . S$ & $58 \pm 8,23$ & $60,19 \pm 7,79$ & 0,249 \\
\hline & $\begin{array}{c}\text { Med } \\
(\min -\max )\end{array}$ & $57,5(41-75)$ & $59(48-79)$ & $(\mathrm{t}=-1,162)$ \\
\hline \multirow[t]{2}{*}{ Cinsiyet (\%) } & Kadın & $27(\% 75)$ & $27(\% 75)$ & $1\left(x^{2}=0\right)$ \\
\hline & Erkek & $9(\% 25)$ & 9 (\%25) & \\
\hline \multirow[t]{2}{*}{ VKİ (kg/m²) } & A.O $\pm S . S$ & $30,17 \pm 4,63$ & $32,66 \pm 5,55$ & $0,043^{*}$ \\
\hline & $\begin{array}{c}\text { Med } \\
(\min -\max )\end{array}$ & $\begin{array}{c}29,62 \\
(22,8-40,15)\end{array}$ & $\begin{array}{c}31,6 \\
(24-44,4)\end{array}$ & $(\mathrm{t}=-2,065)$ \\
\hline
\end{tabular}

${ }^{*} p<0,05$ istatistiksel olarak anlamlı farklılık; $t$ : Iki Ortalama arasındaki farkın önemlilik testi test değeri; VKi = Vücut Kitle indeksi; S.S: Standard Sapma; A.O: Aritmetik Ortalama; Med (min - maks): Ortanca (en küçük - en büyük değerler)

Çalışmaya katılan evre 3 diz OA hastalarının VKi $\quad(p=0,009)$. Ayrıca evre 3 olan hastaların öz-etkililik değerleri, evre 2 hastalarına göre anlamlı derecede yüksek bulundu $(p=0,043)$. Çalışmaya katılan evre 3 diz OA hastalarının TKÖ değerleri, evre 2 değerleri evre 2 diz OA olan hastalara göre anlamlı olarak düşük bulundu ( $p=0,011$ ) (Tablo 2).

Evre 2 ve evre $3 \mathrm{diz} \mathrm{OA}^{\prime}$ sı olan hastaların grubundakilere göre anlamlı olarak yüksek bulundu WOMAC sonuçları ile TKÖ sonuçları arasında orta 
derecede anlamlı pozitif korelasyon bulundu ( $p=$ 0,$048 ; r=0,332$ ). Ayrıca TKÖ sonuçlarının AÖÖ sonuçları ile orta derecede negatif istatistiksel olarak anlamlı bir ilişki olduğu görüldü $(p=0,002 ; r=-0,499$, $p=0,019 ; r=-0,390)$. Bu ilişki evre 2 diz OA' । bireylerde evre 3 olanlara göre daha güçlüdür. Evre 2 hastalarının VAS değerleri ile WOMAC arasında ilişki bulunmazken ( $p=0,281 ; r=0,184)$, evre 3 olan hastalarında istatistiksel olarak anlamlı pozitif korelasyon görüldü ( $p=0,017 ; r=0,397)$ (Tablo 3 ).

Tablo 2. Radyolojik şiddet ile ağrı, fonksiyonel durum, kinezyofobi ve öz etkililik arasındaki ilişki.

\begin{tabular}{|c|c|c|c|c|}
\hline & & Evre 2 & Evre 3 & $p$ \\
\hline \multirow{2}{*}{$\begin{array}{l}\text { VAS } \\
(0-10)\end{array}$} & $A O \pm S . S$ & $6,65 \pm 2,12$ & $6,96 \pm 2,12$ & \multirow{2}{*}{$\begin{array}{c}0,467 \\
(z=-0,727)\end{array}$} \\
\hline & Med $(\min -\max )$ & $7,1(1,5-10)$ & $7,5(1,5-10)$ & \\
\hline \multirow{2}{*}{$\begin{array}{l}\text { WOMAC (0- } \\
96)\end{array}$} & $A O \pm S . S$ & $39,72 \pm 21,02$ & $47,78 \pm 21,31$ & \multirow{2}{*}{$\begin{array}{c}0,111 \\
(t=-1,616)\end{array}$} \\
\hline & $\operatorname{Med}(\min -\max )$ & $\begin{array}{c}38,5 \\
(4,16-97,91)\end{array}$ & $\begin{array}{c}46,4 \\
(9,37-98,95)\end{array}$ & \\
\hline \multirow{2}{*}{$\begin{array}{l}\text { TKÖ } \\
(17-68)\end{array}$} & $\mathrm{AO} \pm \mathrm{S} . \mathrm{S}$ & $43,48 \pm 5,3$ & $46,44 \pm 3,91$ & \multirow{2}{*}{$\begin{array}{c}0,009^{*} \\
(\mathrm{t}=-2,697)\end{array}$} \\
\hline & Med (min - max) & $43(32-57)$ & $46(38-54)$ & \\
\hline \multirow{2}{*}{$\begin{array}{l}\text { AÖÖ } \\
(20-200)\end{array}$} & $\mathrm{AO} \pm \mathrm{S} . \mathrm{S}$ & $151,67 \pm 22,8$ & $136,14 \pm 2,69$ & \multirow[t]{2}{*}{$0,011^{*}(\mathrm{t}=2,597)$} \\
\hline & Med (min - max) & $156(94-182)$ & $142(67-188)$ & \\
\hline
\end{tabular}

${ }^{*} p<0.05$ Istatistiksel olarak anlamlı farklıık; $t$ : Iki Ortalama arasındaki farkın önemlilik testi test değeri; z: Mann Whitney U testi test değeri; VAS=Vizüel Anolog Skalası; WOMAC=Western Ontario ve MacMaster Üniversitesi Osteoartrit Indeksi; TKÖ=Tampa Kinezyofobi Ölçeği; AÖÖ=Artritlerde Özetkililik Ölçeği; A.O: Aritmetik Ortalama; S.S: Standart Sapma; Med (min - maks): Ortanca (en küçük - en büyük değerler)

Tablo 3. Ağrı, fonksiyonel durum, kinezyofobi ve öz etkililik arasındaki ilişki.

\begin{tabular}{lccccccc}
\hline & \multicolumn{5}{c}{ Evre 2 } & \multicolumn{3}{c}{ Evre 3 } \\
\hline & & WOMAC & TKÖ & AÖÖ & WOMAC & TKÖ & AÖÖ \\
\hline $\begin{array}{l}\text { VAS } \\
(\mathbf{0 - 1 0 )}\end{array}$ & $\mathrm{r}$ & 0,184 & 0,155 & $-0,087$ & $0,397^{*}$ & 0,224 & $-0,125$ \\
\cline { 2 - 8 } $\begin{array}{l}\text { WOMAC } \\
(\mathbf{0}-96)\end{array}$ & $\mathrm{p}$ & 0,281 & 0,367 & 0,615 & 0,017 & 0,190 & 0,469 \\
\hline $\begin{array}{l}\text { TKÖ } \\
(\mathbf{2 0 - 2 0 0 )}\end{array}$ & $\mathrm{r}$ & 1 & $0,332^{*}$ & $-0,580^{* *}$ & 1 & $0,376^{*}$ & $-0,426^{* *}$ \\
\hline
\end{tabular}

${ }^{*} p<0,05$ istatistiksel olarak anlamlı ilişki; Spearman korelasyon analizi; VAS=Vizüel Anolog Skalası; WOMAC=Western Ontario ve MacMaster Universitesi Osteoartrit Indeksi; TKÖ=Tampa Kinezyofobi Ölçeği

\section{TARTIŞMA}

Çalışmamızda diz osteoartriti olan bireylerde kinezyofobinin ve kişinin aktivite yapabileceğine olan inancını ifade eden öz-etkililiğin fonksiyonel durumu etkileyen belirteçlerden biri olduğunu bulduk. Diz OA şiddeti artıkça ve hastanın fonksiyonel durumu kötüleştikçe kinezyofobinin arttığı, öz-etkililiğin ise azaldığı ve kinezyofobi ile öz-etkililik arasında negatif ilişki olduğu görüldü.

Osteoartrit genellikle 50 yaşından sonra semptomatik hale gelir; bu yaşlar aynı zamanda radyografik değişikliklerin daha belirgin hale geldiği zamandır (Loeser, 2013). Obezite, diz OA'sının iyileşmesi ve ilerlemesi ile bağlantılı en güçlü risk faktörü olarak belirtilmektedir (Sanghi, Srivastava, Singh ve ark., 2011). Bizim çalışmamızda da yaş ortalamalarının 50' nin üzerinde olduğu, vücut kitle indeksi ortalamalarının da 30 ' un üzerinde olduğu görülmektedir.
Korkudan kaçınma modeline göre, ağrılarını doku hasarı veya yaralanmasının bir semptomu olarak açıklayan hastalar, hareket etmekten korkar ve sonuç olarak normal aktivitelerden kaçınırlar, böylece yaralanma olasılıkları artar (Thompson, Moula ve Woby, 2017). Scopaz ve arkadaşlarının diz OA' Iı 182 hastada yaptıkları değerlendirmeler sonucu yüksek korku kaçınma davranışının fonksiyonel durumda azalma ile ilişkili olduğu bulunmuştur (Scopaz, Piva, Wisniewski ve ark., 2009). Çalışmamızda da bunu destekler şekilde yüksek kinezyofobi skoru olan kişilerin fonksiyonel durumlarının kötü olduğu bulunmuştur. Bu sonuçlar kinezyofobisi olan diz OA'lı bireylerin günlük yaşam aktivitelerindeki faaliyetlere katılırken korku ile yaklaşıp, fonksiyonel sıkıntılar yaşamasının muhtemel olduğunu göstermektedir.

Çalışmamızdaki evre 3 hastalarında ağrı ve fonksiyonel durumları arasında anlamlı ilişki bulunması ağrının fiziksel fonksiyonu etkilediğinin bir göstergesidir. Diz OA' ı bireylerde ağrı algısı, hem 
hastalık sürecini hem de bireyin psikososyal yapısını ve ağrı nörofizyolojisini içeren çok değişkenli bir yapıdır (Odole, Ekediegwu, Ekechukwu ve ark., 2019). Diz OA' I hastalarda çeşitli psikososyal faktörlerin (öz-etkililik, kaygı, sosyal destek, kinezyofobi, çaresizlik, ağrı felaketi, depresyon vb.) ağrı algısı ve fiziksel işlevleri etkilediği bildirilmiştir. Fakat Erden ve arkadaşlarının 80 diz OA'lı hastada kinezyofobi, ağrı, depresyon ve yaşam kalitesini inceledikleri çalışmada, kinezyofobi ile ağrı arasında ilişki bulunamamıştır (Erden, Altuğ, Malkoç ve ark., 2016). Bizim sonuçlarımızda da bu çalışmayı destekler nitelikte sonuçlar bulunması diz osteoartritli bireylerde korku kaçınmaya sebep olan ağrının dışında başka etmenlerde olabileceğini düşündürmektedir. Rayahın ve arkadaşlarının yaptığı başka bir çalışmada düşük ağrı puanının daha yüksek öz-etkililik sonucu ile ilişkili olduğunu bulmuşlardır (Rayahin, Chmiel, Hayes ve ark., 2014). Sonuçlarımıza göre özetkililik ile ağrı arasındaki anlamlı bir ilişki bulunamaması, kişinin aktiviteleri yapabileceğine olan inancının başka faktörlerden de etkilendiğini, değerlendirme ve tedavilerde primer odak noktasının her zaman ağrı olmaması gerektiğini göstermektedir. Brisson ve arkadaşları 45-70 yaş aralığındaki diz osteoartritli hastalarda yaptıkları araştırmada fiziksel fonksiyon ile öz-etkililiğin ilişkili olduğu sonucuna varmışlardır (Brisson, Gatti, Stratford ve ark., 2018). Odole ve arkadaşlarının 89 diz OA' Iı hastayı değerlendirdiği çalışmada daha iyi fonksiyonel durumun yüksek öz-etkililik ve düşük kinezyofobi skorlarıyla ilişkili olduğu bulunmuştur (Odole, Ekediegwu, Ekechukwu ve ark., 2019). Buna göre öz-etkililiği iyi olan ve kinezyofobisi daha düşük olan bireylerin fonksiyonel durumları daha iyi olacağı için günlük yaşamdaki aktivitelere daha fazla katılım gösterebilecekleri düşünülmektedir. Marks ve arkadaşlarının artrit hastalarında öz-etkililik ve artrit sonuçları arasındaki ilişkiyi inceledikleri çalışmalarında, öz-etkililiği arttırma stratejilerinin engellilik ve genel sağlık üzerinde olumlu bir etkisi olduğu sonucuna varmışlardır (Marks, 2001). Çalışmamızda diz OA şiddeti evre $3 \mathrm{diz}$ olan hastaların öz etkililik sonuçlarının evre 2'dekilere göre daha düşük olması bu sonucu desteklemektedir.

Çalışmadan elde ettiğimiz sonuca göre radyolojik seviye artıkça bireylerin ağrı şikayetlerinin artış göstermediği görülmüştür. Literatüre bakıldığında radyolojik değerlendirmeler ile diz osteoartritli bireylerin ağrı şikayetleri ve fonksiyonel durum arasındaki ilişkileri inceleyen çalışmalarda bir fikir birliği bulunmamaktadır (Kittelson, George, Maluf ve ark., 2014; Serban, Porojan, Deac ve ark., 2016; Talic-Tanovic, Hadziahmetovic, Madjar-Simic ve ark., 2017). Popülasyon çalışmaları da, radyografik eklem hasarı gösteren yetişkinlerin yalnızca yarısının osteoartrit semptomları yaşadığını göstermiştir (Wright, Zautra ve Going, 2008). Ayrıca çalışmamızda evreler arası fonksiyonel durum açısından anlamlı bir fark olmasa da vücut kitle indeksleri daha fazla olan evre 3'deki bireylerin fonksiyonel durumlarının daha kötü olduğu görülmüştür. Bu da obezitenin bireylerin fonksiyonel durumlarını olumsuz yönde etkileyebileceğini göstermektedir. Bakırhan ve arkadaşlarının diz osteoartritli hastaların fonksiyonel özelliklerini değerlendirdikleri çalışmalarında da aşırı kilo nedeniyle fonksiyonel durumlarının kısıtlandığını belirtmişlerdir (Bakırhan, Bozan, Ünver ve ark., 2017).

Çalışmamızda sadece evre 2 ve evre $3 \mathrm{diz}$ osteoartritli hastaları değerlendirmemiz çalışmamızın bir limitasyonudur. Gelecek çalışmalarda bütün evrelere ait hastaları değerlendirmek ve aynı zamanda katıımcı sayılarını artırmak çalışmamızda bulduğumuz sonuçları güçlendirmek ve çıkarılan sonuçları diz osteoartritli hastaların geneline yayılması açısından önemli olacaktır.

$\mathrm{Bu}$ çalışmanın sonucunda diz osteoartritli bireylerde kinezyofobi ve öz-etkililik durumunun fonksiyonel durumunu etkileyen bir faktör olduğu ve ağrının dışında bu parametrelerin de bireyin hem değerlendirmesinde hem de tedavi planlaması yapılırken dikkat edilmesi gereken faktörler olduğu görülmüştür. Kinezyofobi ve öz-etkililiğin diz osteoartritinin radyolojik şiddetine göre değiştiği görüldü. Dolayısıyla bu sonuçlar diz osteoartritli bireylerde radyolojik şiddetin artmasıyla beraber kinezyofobinin artmaması, öz-etkililiğin ise azalmaması için klinisyenlerin önlem alması gerektiğini göstermektedir.

\section{Etik Onay}

$\mathrm{Bu}$ çalışma için Hacettepe Üniversitesi Girişimsel Olmayan Klinik Araştırmalar Etik Kurulu tarafından 20 Mart 2018 tarihli 2018/08 toplantısında, GO 18/129-12 kayıt numarası ile onay alınmıştır.

\section{Araştırmacıların Katkı Oranı}

Fikir: NK, Tasarım: NK, GC, Veri toplama: NK, IB, Analiz: NK, GC, IB, Makale yazımı: NK, GC, IB, Eleştirel inceleme: GC, IB

\section{Çıkar Çatışması Beyanı}

Yazarlar, bu makalenin yazarı ve / veya 
yayınlanmasıyla ilgili herhangi bir çıkar çatışması beyan etmemişlerdir.

\section{Destek/Teşekkür}

Yoktur.

\section{Kaynaklar}

Areeudomwong, P., \& Buttagat, V. (2017). Reliability and validity of the cross-culturally adapted thai version of the tampa scale for kinesiophobia in knee osteoarthritis patients. Malays J Med Sci, 24(2), 61-67.

Araujo, I. L. A., Castro, M. C., Daltro, C., \& Matos, M. A. (2016). Quality of life and functional independence in patients with osteoarthritis of the knee. Knee Surg Relat Res, 28(3), 219.

Bakırhan, S., Bozan, O., Ünver, B., \& Karatosun, V. (2017). Evaluation of functional characteristics in patients with knee osteoarthrit,s. Acta Ortop Bras, 25(6), 248-252.

Benyon, K., Hill, S., Zadurian, N., \& Mallen, C. (2010). Coping strategies and self-efficacy as predictors of outcome in osteoarthritis: a systematic review. Musculoskeletal Care, 8(4), 224-36.

Brady, T. J. (2011). Measures of self-efficacy: arthritis selfefficacy scale (ases), arthritis self-efficacy scale-8 Item (ases-8), children's arthritis self-efficacy scale (case), chronic disease self-efficacy scale (cdses), parent's arthritis self-efficacy scale (pase), and rheumatoid arthritis self-efficacy scale (RASE). Arthritis Care Res (Hoboken) 63 Suppl, 11, S473-485.

Brand, E., Nyland, J., Henzman, C., \& McGinnis, M. (2013). Arthritis self-efficacy scale scores in knee osteoarthritis: A systematic review and meta-analysis comparing arthritis self-management education with or without exercise. J Orthop Sports Phys Ther, 43(12), 895-910.

Brisson, N. M., Gatti, A. A., Stratford, P. W., \& Maly, M. R. (2018). Self-efficacy, pain, and quadriceps capacity at baseline predict changes in mobility performance over 2 years in women with knee osteoarthritis. J Clin Rheumatol, 37(2), 495-504.

Cruz-Almeida, Y., King, C. D., Goodin, B. R., Sibille, K. T., Glover, T. L., Riley, J. L., et al. (2013). Psychological profiles and pain characteristics of older adults with knee osteoarthritis. Arthritis Care Res, 65(11), 17861794.

Doğan, N., Göriş, S., \& Demir, H. (2016). Levels of pain and self-efficacy of individuals with osteoarthritis. Agri, 28(1), 25-31.

Erden, A., Altuğ, F., Malkoç, A., \& Kocabal, A. (2016). Diz osteoartritli bireylerde kinezyofobi, ağrı siddeti, anksiyete-depresyon durumu ve yaşam kalitesinin incelenmesi. Uluslararası hakemli ortopedi travmatoloji ve spor hekimliği dergisi, 7, 1-15

Harrison, A. L. (2004). The influence of pathology, pain, balance, and self-efficacy on function in women with osteoarthritis of the knee. Phys Ther, 84(9), 822-831.

Hatfield, G.L., Morrison, A., Wenman, M., Hammond, C.A, \& Hunt, M.A. (2016). Clinical tests of standing balance in the knee osteoarthritis population: systematic review and meta-analysis. Phys Ther, 96(3), 324-37.

Kittelson, A. J., George, S. Z., Maluf, K. S., \& StevensLapsley, J. E. (2014). Future directions in painful knee osteoarthritis: harnessing complexity in a heterogeneous population. Phys Ther, 94(3), 422-432.

Lawson, T., Morrison, A., Blaxland, S., Wenman, M., Schmidt, C. G., \& Hunt, M. A.(2015). Laboratory-based measurement of standing balance in individuals with knee osteoarthritis: a systematic review. Clin Biomech, 30(4), 330-342.

Loeser, R. F. (2013). Aging processes and the development of osteoarthritis. Curr Opin Rheumatol, 25(1), 108-113.
López-Bravo, M.D., Zamarrón-Cassinello, M.D., Touche, R.L., Muñoz-Plata, R., Cuenca-Martínez, F., \& Ramos-Toro, M. (2020). Psychological factors associated with functional disability in patients with hip and knee osteoarthritis, Behav Med, 10, 1-11

Marks, R. (2001). Efficacy theory and its utility in arthritis rehabilitation: review and recommendations. Disabil Rehabil, 23(7), 271-280.

Neogi, T., Guermazi, A., Roemer, F., Nevitt, M. C., Scholz, J., Arendt-Nielsen, L., et al. (2016). Association of joint Inflammation with pain sensitization in knee osteoarthritis: The multicenter osteoarthritis study. Arthritis Rheumatol, 68(3), 654-661.

Odole, A., Ekediegwu, E., Ekechukwu, E. N. D., \& Uchenwoke, C. (2019). Correlates and predictors of pain intensity and physical function among individuals with chronic knee osteoarthritis in Nigeria. Musculoskelet Sci Pract, 39, 150156.

Oiestad, B. E., White, D. K., Booton, R., Niu, J., Zhang, Y., Torner, J., et al. (2016). Longitudinal course of physical function in people with symptomatic knee osteoarthritis: Data from the multicenter osteoarthritis study and the osteoarthritis Initiative. Arthritis Care Res (Hoboken), 68(3), 325-331.

Pouli, N., Das Nair, R., Lincoln, N. B., \& Walsh, D. (2014). The experience of living with knee osteoarthritis: Exploring illness and treatment beliefs through thematic analysis. Disabil Rehabil, 36(7), 600-607.

Rayahin, J. E., Chmiel, J. S., Hayes, K. W., Almagor, O., Belisle, L., Chang, A. H., et al. (2014). Factors associated with pain experience outcome in knee osteoarthritis. Arthritis Care Res (Hoboken), 66(12), 1828-1835.

Sanchez-Heran, A., Agudo-Carmona, D., Ferrer-Pena, R., Lopezde-Uralde-Villanueva, I., Gil-Martinez, A., Paris-Alemany, A., et al. (2016). Postural stability in osteoarthritis of the knee and hip: analysis of association with pain catastrophizing and fear-avoidance beliefs. $P M R, 8(7), 618-628$.

Sanghi, D., Srivastava, R. N., Singh, A., Kumari, R., Mishra R., \& Mishra A. (2011). The association of anthropometric measures and osteoarthritis knee in non-obese subjects: a cross sectional study. Clinics (Sao Paulo), 66(2), 275-279.

Scopaz, K. A., Piva, S. R., Wisniewski, S., \& Fitzgerald, G. K. (2009). Relationships of fear, anxiety, and depression with physical function in patients with knee osteoarthritis. Arch Phys Med Rehabil, 90(11), 1866-1873.

Serban, O., Porojan, M., Deac, M., Cozma, F., Solomon, C., Lehghel, M., et al. (2016). Pain in bilateral knee osteoarthritis-correlations between clinical examination, radiological, and ultrasonographical findings. Med Ultrason, 18(3), 318-325.

Shelby, R. A., Somers, T. J., Keefe, F. J., DeVellis, B. M., Patterson, C., Renner, J. B., et al. (2012). Brief fear of movement scale for osteoarthritis. Arthritis Care Res (Hoboken), 64(6), 862-871.

Talic-Tanovic, A., Hadziahmetovic, Z., Madjar-Simic, I., \& Papovic, A. (2017). Comparison of clinical and radiological parameters at knee osteoarthritis. Med Arch, 71(1), 48.

Thompson, D. P., Moula, K., \& Woby, S. R. (2017). Are fear of movement, self-efficacy beliefs and fear of falling associated with levels of disability in people with osteoarthritis of the knee? A cross sectional study. Musculoskeletal Care, 15(3), 257-262.

Tüzün, E., Eker, L., Aytar, A., Daşkapan, A., \& Bayramoğlu, M. (2005). Acceptability, reliability, validity and responsiveness of the Turkish version of WOMAC osteoarthritis index. Osteoarthritis cartilage, 13(1), 28-33.

Ünsal, A., \& Kaşıkçı, M. (2008). Artritli bireylerde öz-etkililik ölçeği'nin geçerlik ve güvenirliliği. Journal of Anatolia Nursing and Health Sciences, 11(1), 40-50.

Wright, L. J., Zautra, A. J., \& Going, S. (2008). Adaptation to early knee osteoarthritis: the role of risk, resilience, and disease severity on pain and physical functioning. Ann of Behav Med, 36(1), 70-80

Yılmaz, Ö. T., Yakut, Y., Uygur, F., \& Uluğ, N. (2011). Tampa kinezyofobi ölçeği'nin Türkçe versiyonu ve test-tekrar test güvenirliği. Turk J Physiother Rehabil, 22(1), 44-49. 